\title{
Legal Aspect of Teleradiology at Hospital in Fulfillment of Patient Right
}

Aspek Hukum Pelaksanaan Teleradiologi Di Rumah Sakit Dalam Pemenuhan Hak Pasien

\author{
Adrian Benhard Mardi Putra, Trihoni Nalesti Dewi, Daniel Budi Wibowo \\ email: adrianbenhard@hotmail.com
}

Health Law Master Program, Soegijapranata Catholic University of Semarang

\begin{abstract}
The geographical situation and the disparity of the radiologist distribution make access to radiology services in rural, remote and island areas unmet. The presence of teleradiology can eliminate such gaps by increasing the speed and accuracy of diagnoses through technological assistance carried out in stages through the regulation of the telemedicine pilot project. Although teleradiology is currently still limited to trials, it is necessary to consider legal aspects, such as fairness, usefulness and legal certainty to the fulfillment of patient rights.

This study is sociological-juridical with explanatory research specification. This study uses primary data obtained from in-depth interview to 6 informants consisting of 1 region head IDI, one head of medical support head, 1 ICT legal expert, with one radiologist with two radiographers who is performing teleradiology. Meanwhile, secondary data as media supporting obtained through by literature and legislation review. Furthermore, data obtained are processed and analyzed qualitatively.
\end{abstract}

Based on the results of research in dr. Wahidin Sudirohusodo Makassar Hospital and H.A. Sulthan Daeng Radja Bulukumba Hospital, the implementation of teleradiology in both hospitals resulted in some of the patient's rights being unfulfilled due to infrastructure constraints, limited human resources and lack of socialization. Patients are not entitled to informed consent and the provision of medical information. The right to the second opinion is also not fulfilled so that the patient does not get a chance to seek a second chance on the diagnosis of his illness. The non-fulfillment of both rights also affects the right to patient safety in the hospital in the case of management and taking action due to incomplete medical record data. As for the legal aspects to be achieved in the implementation of teleradiology, i.e., equity, usefulness, and legal certitude aspect. However, from these three aspects, the legal certitude aspect is not implemented properly as part of the fulfillment of patient rights due to existing regulations not to set certain things that can provide legal protection for provider or recipient of teleradiology service.

Keywords: legal aspect, implementation of teleradiology, patient right fulfillment 


\section{PENDAHULUAN}

Kesehatan sebagai hak asasi manusia dikenal juga dengan istilah hak atas kesehatan yang telah dijamin dan diatur di berbagai regulasi internasional maupun nasional, seperti pada Deklarasi Universal tentang Hak Asasi Manusia dan Konvensi Internasional tentang Penghapusan Segala Bentuk Diskriminasi Rasial serta pada Undang-Undang Dasar 1945 dan Undang-Undang Nomor 39 Tahun 1999 tentang Hak Asasi Manusia. Negara adalah pihak yang bertanggungjawab atas pemenuhan hak tersebut sebab kesehatan menjadi tolak ukur bagi setiap orang untuk dapat memenuhi hak-haknya yang lain. Tanggungjawab pemerintah tersebut lazimnya dikenal dengan kerangka tipologi tripatri ${ }^{1}$ yang berkaitkan dengan kewajiban negara dalam pemenuhan hak atas kesehatan.

Saat ini dengan jumlah populasi penduduk lebih dari 255 juta jiwa dan letak wilayah geografis Indonesia sebagai negara kepulauan yang terdiri dari 17.100 pulau $^{2}$, maka upaya pelayanan kesehatan kemudian dihadapkan pada permasalahan penting yaitu peningkatan pelayanan kesehatan yang berkualitas, setara dan mudah diakses. Meskipun rasio dokter spesialis sudah mencapai target namun ketidakmerataan distribusi tersebut masih cukup besar oleh karena mayoritas memilih untuk bekerja di kota-kota besar sehingga mengakibatkan persebaran di daerah perbatasan atau bahkan pedalaman mengalami disparitas dengan rasio terendah berada di Papua (3,0 per 100.000) dan tertinggi di DKI Jakarta $\left(52,2\right.$ per 100.000). ${ }^{3}$

Ketidakmerataan tersebut dapat diatasi dengan bantuan teknologi yang komprehensif, efisien dan efektif antara tenaga kesehatan dan rumah sakit. Salah satu pengembangan teknologi informasi dan komunikasi dalam bidang kesehatan adalah teleradiologi. Teleradiologi adalah bagian dari telemedicine $e^{4}$ dengan menggunakan konsep store-andforward (asynchronous) sehingga tidak memerlukan kehadiran para pihak dalam waktu bersamaan untuk melakukan pertukaran data dan informasi medis. ${ }^{5}$

Menurut Menteri Kesehatan kini di beberapa rumah sakit juga tengah dikembangkan pilot project telemedicine yaitu teleradiologi, telekardiologi, radio komunikasi medik

\footnotetext{
1 Tipologi tripatri adalah sebuah kerangka yang secara khusus membedakan kewajiban negara untuk menghormati, melindungi, dan memenuhi setiap hak asasi manusia. Dasar asumsinya adalah kewajiban negara untuk menghormati (respect) adalah kewajiban esensial negatif untuk menahan diri dalam mengambil tindakan, kewajiban untuk melindungi (protect) adalah kewajiban positif untuk melindungi individu terhadap tindakan tertentu oleh pihak ketiga, dan memenuhi (fulfill) adalah untuk menyediakan atau memudahkan pelayanan bagi setiap warga. Dian Noeswantri,: "Pemenuhan Hak Anak Dalam Perspektif HAM”, 2004, Dinamika HAM, Volume 4, Nomor 1, Januari 2004, ISSN 1410-3982, hlm. 49.

${ }^{2}$ Profil Kesehatan Indonesia 2015, Kementerian Kesehatan RI, hlm. 1.

${ }^{3}$ Wisnubro, "Sebanyak 1.250 Dokter Spesialis akan Disebar ke Pelosok Tanah Air" 24 Februari 2017, diakses pada 29 Agustus 2017, https://jpp.go.id/humaniora/kesehatan/302825-inilah-program-kemenkes-agar-tenagakesehatan-merata-di-tanah-air

${ }^{4}$ The literal meaning is "health[care] at a distance". Thus, telemedicine may represent health care practised in real time, using a video link for example, or asynchronously, perhaps by email. The type of health care interaction is perfectly general, and may encompass diagnosis and management education of staff, patients and the general population and administrative meetings. Richard Wotton, et.al., 2009, Telehealth in the Developing World, London: Royal Society of Medicine Press Ltd., $p 3$.

5 World Health Organization,: "Telemedicine: Opportunities and Developments in Member States: (Report On The Second Global Survey On eHealth)", 2010, WHO Press: Global Observatory for eHealth Series, Volume 2, 2009 ISSN 2220-5462., p.10.
} 
(teleconference), video conference (vicon), teleradiotherapy, dan sebagainya. ${ }^{6}$ Pemenuhan telemedicine diprioritaskan untuk meningkatkan akses pelayanan kesehatan yang berkualitas di DTPK. ${ }^{7}$ Teleradiologi merupakan salah satu upaya inovatif dari pemerintah dalam mengatasi keterbatasan tenaga spesialis-subspesialis terutama dalam memperkuat pelayanan kesehatan dasar dan rujukan di fasilitas pelayanan kesehatan.

American College of Radiology (ACR) mendefinisikan teleradiologi sebagai “...transmisi elektronik gambar radiologis dari satu lokasi ke lokasi lain untuk tujuan interpretasi dan/atau konsultasi". ${ }^{8}$ Sebagai teknologi pengolahan dan anaslis citra/foto medis, teleradiologi dapat membantu penanganan pasien secara cepat sehingga bisa mengurangi resiko yang ditimbulkan akibat tindakan yang terlambat. Hal ini memungkinkan dokter untuk menerima atau mengirim gambar/foto radiologi sehingga dapat mempermudah komunikasi antara dokter dan rumah sakit untuk menegakkan diagnosis secara cepat, tepat dan terarah.

Program uji coba teleradiologi pertama kali dilaksanakan melalui Keputusan Direktur Jenderal Bina Upaya Kesehatan Kementerian Kesehatan Nomor HK.02.03/V/0209/2013 tentang Pelaksanaan Pilot Project Telemedicine dan Penunjukan Fasilitas Pelayanan Kesehatan Telemedicine Bidang Teleradiologi dan Telekardiologi. Kemudian berlanjut dengan Keputusan Menteri Kesehatan Nomor HK.02.02/Menkes/409/2016 tentang Rumah Sakit Uji Coba Program Pelayanan Telemedicine Berbasis Video-Conference dan Teleradiologi. Saat ini yang terbaru melalui Keputusan Menteri Kesehatan Nomor HK.01.07/Menkes/650/2017 tentang Rumah Sakit dan Puskesmas Penyelenggara Uji Coba Program Pelayanan Telemedicine.

Sementara itu pemanfaatan teknologi bidang kesehatan tumbuh sedemikian cepat disertai dengan semakin kompleksnya permasalahan dalam rumah sakit maka tenaga kesehatan wajib merespon kondisi tersebut, hal ini dikarenakan peran dokter dan tenaga kesehatan lainnya dalam pemanfatan teleradiologi menjadi krusial sebab dibutuhkan keahlian khusus, pendidikan berkelanjutan maupun pengalaman yang memadai serta etika profesi yang tinggi. Adanya aspek hukum dalam pelaksanaan teleradiologi patut dipertimbangkan untuk menjaga agar hak pasien tetap terpenuhi sesuai dengan ketentuan peraturan perundangundangan yang berlaku. Maka dengan demikian juga diperlukan sebuah regulasi khusus untuk dapat memberikan jaminan keadilan, kemanfaatan dan kepastian hukum.

\footnotetext{
${ }^{6}$ Berita ini disiarkan oleh Pusat Komunikasi Publik Sekretariat Jenderal Kementerian Kesehatan RI, "Menkes Harapkan Kemkominfo Dukung Pemanfaatan Teknologi Informasi Dan Komunikasi (TIK) Di Bidang Kesehatan", 31 Desember 2014, diakses pada 14 Maret 2017, http://www.depkes.go.id/article/print/15010200022/menkesharapkan-kemkominfo-dukung-pemanfaatan-teknologi-informasi-dan-komunikasi-tik-di-bidang-keseh.html

${ }^{7}$ DTPK (Daerah Tertinggal, Perbatasan dan Kepulauan) berdasarkan RPJMN 2010-2015 ditetapkan terdapat 183 kabupaten tertinggal di 27 provinsi, dan ditetapkan 92 Pulau-Pulau kecil terluar yang menjadi titik pangkal penetapan wilayah NKRI serta 34 Pulau-Pulau Kecil Terluar Berpenduduk yang memerlukan pelayanan kesehatan dasar (data Perpres 78 tahun 2005). Selain itu sebanyak 12 Provinsi, 35 kabupaten/kota, terutama di Kalbar, Kaltim, NTT dan Papua yang berhadapan langsung dengan negara tetangga. Diakses pada 20 April 2017, https://rebanas.com/kamus/kesehatan/dtpk-daerah-tertinggal-perbatasan-dan-kepulauan

8 American College of Radiology, "ACR Standard for Teleradiology", diakses pada 28 September 2017, https://www.acr.org/Practice-Management-Quality-Informatics/Legal-Practices/Teleradiology
} 


\section{PERUMUSAN MASALAH}

1. Bagaimanakah pelaksanaan teleradiologi di rumah sakit dalam pemenuhan hak pasien?

2. Bagaimanakah aspek hukum pelaksanaan teleradiologi di rumah sakit dalam pemenuhan hak pasien?

\section{METODE PENELITIAN}

Penelitian ini menggunakan metode sosiologis yuridis dengan spesifikasi penelitian eksplikatif eksploratif. Jenis data terdiri dari data primer yaitu hasil wawancara dengan narasumber, serta data sekunder yaitu teori yang diperoleh dari buku serta peraturan perundang-undangan sesuai dengan judul tesis. Penelitian ini dilaksanakan pada dua rumah sakit di Provinsi Sulawesi Selatan, yaitu RSUP dr. Wahidin Sudirohusodo Makassar dan RSUD H.A. Sulthan Daeng Radja Bulukumba. Metode pengumpulan data yaitu mewawancara dengan narasumber yaitu: ketua IDI Kota Makassar, kepala bagian penunjang medik, 1 akar hukum ITE, serta 1 dokter spesialis radiologi dan 2 radiografer. Metode analisis data menggunakan kualitatif.

\section{PEMBAHASAN}

\section{Pelaksanaan Teleradiologi dalam Pemenuhan Hak Pasien}

Idealnya, setiap warga negara harus memiliki akses langsung ke dokter spesialis untuk melakukan konsultasi dan mendapatkan pelayanan medis namun, status layanan kesehatan saat ini yang sedemikian rupa sehingga pelayanan medis tidak dapat menjangkau daerah pedesaan atau terpencil. Pada kenyataannya belum semua rumah sakit memiliki dokter spesialis radiologi, keterbatasan infrastruktur dan kondisi geografis yang sulit seringkali menyebabkan keterlambatan penanganan pasien. Pasal 5 huruf $d$ Undang-Undang Nomor 44 Tahun 2009 tentang Rumah Sakit menyebutkan bahwa: rumah sakit sebagai penyelenggaraan penelitian dan pengembangan serta penapisan teknologi bidang kesehatan dalam rangka peningkatan pelayanan kesehatan dengan memperhatikan etika ilmu pengetahuan bidang kesehatan.

Teleradiologi mampu menjembatani kesenjangan akan kebutuhan ekspertise ${ }^{9}$ radiologi bagi rumah sakit yang belum memiliki dokter spesialis radiologi dan second opinion bagi rumah sakit yang telah dipenuhi oleh penugasan dokter residen radiologi dan menunjang proses pembelajaran tanpa perlu berada di lokasi yang sama. Sebab akses terhadap fasilitas pelayanan kesehatan berkualitas adalah hak dasar bagi setiap manusia yang mana agar layanan berkualitas tinggi dapat diakses, maka pemerintah melalui fasilitas kesehatan harus dapat menyediakan layanan yang sesuai dengan kebutuhan dan harapan masyarakat.

Pada bagian lampiran Kepmenkes Nomor 410/Menkes/SK/III/2010 tentang Perubahan Atas Kepmenkes Nomor 1014/Menkes/SK/XI/2008 tentang Standar Pelayanan Radiologi Diagnostik di Sarana Pelayanan Kesehatan disebutkan bahwa yang berhak melaksanakan teleradiologi, konsultasi radiodiagnostik, imejing diagnostik, radiologi intervensional,

\footnotetext{
${ }^{9}$ Ekpertise (hasil pembacaan) adalah gambaran deskripsi dari foto radiologi yang mana pada setiap bagian atau region yang di foto memiliki deskripsi yang berbeda pula.
} 
serta pemeriksaan dan pembacaan hasil radiologi adalah dokter spesialis radiologi. Mengacu pada hal tersebut, maka pemerintah kemudian menunjuk beberapa rumah sakit untuk kemudian melaksanakan uji coba teleradiologi ${ }^{10}$, dua diantaranya adalah RSUP dr. Wahidin Sudirohusodo Makassar sebagai rumah sakit pengampu dan RSUD H. Andi Sulthan Daeng Radja Bulukumba sebagai rumah sakit yang diampu.

RSUP dr. Wahidin Sudirohuso Makassar merupakan rumah sakit pengampu bagi RSUD Harapan Insan Sendawar Kalimantan Timur sebagai rumah sakit yang diampu berdasarkan Kepmenkes Nomor HK.02.02/Menkes/409/2016 tentang Rumah Sakit Uji Coba Program Pelayanan Telemedicine Berbasis Video-Conference dan Teleradiologi. Sedangkan RSUD H. Andi Sulthan Daeng Radja Bulukumba merupakan rumah sakit yang diampu oleh RSUPN dr. Cipto Mangunkusumo Jakarta berdasarkan Keputusan Direktur Jenderal Bina Upaya Kesehatan Kemenkes Nomor: HK.02.03/V/0209/2013 Tanggal 31 Januari 2013 tentang Pelaksanaan Pilot Project Telemedicine dan Penunjukan Fasilitas Pelayanan Kesehatan Telemedicine Bidang Teleradiologi dan Telekardiologi.

Pada pelayanan teleradiologi, hak pasien kemudian menjadi lebih spesifik atau mengerucut, dimana dalam penelitian ini ditemukan pelanggaran terhadap hak pasien. Pada pelaksanaannya di lapangan, peneliti menemukan beberapa hal yang menyebabkan hak-hak pasien tidak terpenuhi dalam teleradiologi baik secara langsung maupun tidak langsung, yakni hak atas informed consent, hak atas second opinion, dan hak atas keselamatan pasien di rumah sakit.

\section{a. Hak atas Informed Consent}

Informed consent bukanlah sebuah perjanjian antara dua pihak, melainkan lebih ke arah persetujuan sepihak dalam hal ini oleh pasien atas layanan yang ditawarkan pihak lain, yakni dokter. Hak pasien atas informed consent atau persetujuan tindakan kedokteran merupakan hak legal dan etis yang dimilki oleh setiap pasien untuk dapat menentukan hal yang boleh dan tidak boleh dilakukan terhadap tubuhnya.

Pelaksanaan ekspertise teleradiologi oleh RSUD Harapan Insan Sendawar Kalimantan Timur sebagai rumah sakit yang diampu oleh RSUP dr. Wahidin Sudirohusodo ternyata tidak mendapatkan persetujuan (informed consent) dan tidak juga memberikan informasi mengenai pelayanan teleradiologi yang akan dilakukan kepada pasien maupun keluarganya. Padahal dalam diktum ketujuh angka 2 Kepmenkes Nomor HK.02.02/Menkes/409/2016 tentang Rumah Sakit Uji Coba Program Pelayanan Telemedicine Berbasis Video-Conference dan Teleradiologi dijelaskan bahwa "tugas rumah sakit yang diampu wajib mendapatkan persetujuan (informed consent) dari pihak pasien maupun keluarga pasien sebelum melaksanakan rujukan".

Berikut ini adalah pasal-pasal dalam peraturan perundang-undangan di bidang kesehatan yang mengatur mengenai informed consent atau persetujuan tindakan kedokteran, yakni:

\footnotetext{
${ }^{10}$ Regulasi mengenai uji coba teleradiologi, yakni:

1. Keputusan Direktur Jenderal Bina Upaya Kesehatan Kementerian Kesehatan Republik Indonesia Nomor: HK.02.03/V/0209/2013 Tanggal 31 Januari 2013 tentang Pelaksanaan Pilot Project Telemedicine dan Penunjukan Fasilitas Pelayanan Kesehatan Telemedicine Bidang Teleradiologi dan Telekardiologi,

2. Keputusan Menteri Kesehatan Nomor HK.02.02/Menkes/409/2016 tentang Rumah Sakit Uji Coba Program Pelayanan Telemedicine Berbasis Video-Conference dan Teleradiologi,

3. Keputusan Menteri Kesehatan Nomor HK.01.07/Menkes/650/2017 tentang Rumah Sakit dan Puskesmas Penyelenggara Uji Coba Program Pelayanan Telemedicine.
} 
1) Pasal 45 dan 52 Undang-Undang Nomor 29 Tahun 2004 tentang Praktik Kedokteran

2) Pasal 44 ayat (3) dan 56 ayat (1) Undang-Undang Nomor 36 Tahun 2009 tentang Kesehatan

3) Pasal 32 huruf j dan k Undang-Undang Nomor 44 Tahun 2009 tentang Rumah Sakit

4) Pasal 2 Permenkes Nomor 290/Menkes/Per/III/2008 tentang Persetujuan Tindakan Kedokteran

Maka dengan demikian pelaksanaan teleradiologi tanpa meminta persetujuan atau informed consent termasuk tidak memberikan informasi yang berimbang bagi pihak pasien atau keluarga pasien telah melanggar hak pasien untuk mendapatkan informasi mengenai tindakan yang telah dilakukan atas dirinya. Pentingnya informed consent termasuk mengedukasi pasien mengenai teleradiologi sebelum dilakukan tindakan sehingga pasien dapat mengerti setiap prosedur dan resiko yang timbul.

\section{b. Hak atas Second Opinion}

Second opinion merupakan upaya efektif dalam konteks praktik kedokteran yang dapat diartikan sebagai upaya seorang pasien untuk memperoleh pendapat kedua mengenai diagnosis dirinya sehingga dengan meminta second opinion dari dokter lain dapat memperkecil peluang terjadinya kesalahan diagnosis karena fokus dan tanggungjawab malpraktek dalam teleradiologi hampir pasti akan terjadi karena misdiagnosis. ${ }^{11}$

Adapun pelaksanaan teleradiologi di RSUD H.A. Sulthan Daeng Radja Bulukumba telah vakum sejak tahun 2015 salah satu penyebabnya dikarenakan adanya kesalahpahaman oleh dokter spesialis radiologi dan manajemen rumah sakit yang menganggap teleradiologi tidak perlu dijalankan jika sudah memiliki dokter spesialis radiologi sendiri. Padahal tujuan teleradiologi selain untuk mempercepat penegakan diagnosis, juga untuk memberikan kesempatan bagi pasien untuk mendapatkan second opinion dari dokter spesialis radiologi lain. Hal ini dimaksudkan untuk memastikan keakuratan diagnosis ekspertise foto atau gambar radiologi pasien.

Interpretasi antara satu dokter dengan dokter lainnya bisa berbeda, penentuan diagnosis dan penatalaksanaan tindakan yang berbeda mungkin tidak menjadi masalah yang serius apabila tidak menimbulkan konsekuensi yang merugikan bagi pasien. Dokter spesialis radiologi dalam mengintepetasi foto atau gambar radiologi sedikit banyak dipengaruhi oleh pengalaman, pelatihan dan pendidikan tambahan yang didapatkan serta kepakaran yang berarti ini merupakan sebuah subjektifitas sehingga menjadi penting bagi dokter untuk melakukan second opinion kepada rekan sejawat dan penting bagi pasien untuk mendapatkan haknya atas second opinion agar dapat memastikan diagnosis yang akurat secara objektif.

Berikut ini adalah pasal-pasal dalam peraturan perundang-undangan di bidang kesehatan yang mengatur mengenai second opinion atau pendapat kedua, yakni:

1) Pasal 52 b Undang-Undang Nomor 29 Tahun 2004 tentang Praktik Kedokteran

2) Pasal 32 huruf h Undang-Undang Nomor 44 Tahun 2009 tentang Rumah Sakit

\footnotetext{
${ }^{11}$ Scott Berger and Barry Cepelewicz, 1995, “Medical-Legal Issues in Teleradiology”, American Roentgen Ray Society, p. 507.
} 
Hak pasien atas second opinion atau pendapat kedua merupakan hak dasar pasien yang telah diatur dan dilindungi oleh undang-undang. Meskipun teleradiologi masih sebatas uji coba tetapi sangatlah tidak tepat jika second opinion tidak dilaksanakan atau ditiadakan dalam teleradiologi mengingat jika terjadi kesalahan interpretasi maka juga akan mempengaruhi tindakan selanjutnya.

\section{c. Hak atas Keselamatan Pasien di Rumah Sakit}

Pada teleradiologi, rekam medis menjadi penting karena dokter dan pasien tidak bertemu secara langsung, sehingga hal ini kemudian memunculkan potensi resiko misinterpretasi akibat data klinis berupa rekam medis pasien yang tidak lengkap. Seorang dokter spesialis radiologi membutuhkan rekam medis pasien sebagai pembanding agar dapat menegakkan diagnosis atas ekspertise suatu gambar atau foto radiologi secara akurat.

Pelaksanaan ekspertise teleradiologi oleh RSUD Harapan Insan Sendawar Kalimantan Timur sebagai rumah sakit yang diampu oleh RSUP dr. Wahidin Sudirohusodo pada saat mengirimkan gambar atau foto radiologi untuk dilakukan ekspertise ternyata tidak menyertakan data rekam medis pasien. Hal ini mengakibatkan dokter yang bertugas melayani ekspertise tidak dapat menegakkan diagnosis atas gambar atau foto radiologi tersebut. Padahal dalam diktum ketujuh angka 1 Kepmenkes Nomor HK.02.02/Menkes/409/2016 tentang Rumah Sakit Uji Coba Program Pelayanan Telemedicine Berbasis Video-Conference dan Teleradiologi menyebutkan "tugas rumah sakit yang diampu salah satunya yaitu memberikan informasi medis (rekam medis) pasien kepada rumah sakit pengampu untuk kepentingan proses konsultasi, pendidikan dan penelitian".

Berikut ini adalah pasal-pasal dalam peraturan perundang-undangan di bidang kesehatan yang mengatur mengenai patient safety atau keselamatan pasien di rumah sakit, yakni:

1) Pasal 2 Undang-Undang Praktik Nomor 29 Tahun 2004 tentang Kedokteran

2) Pasal 53 ayat (3) Undang-Undang Nomor 36 Tahun 2009 tentang Kesehatan

3) Pasal 3 huruf b, 13 ayat (3), 32 huruf $n$ dan 43 Undang-Undang Nomor 44 Tahun 2009 tentang Rumah Sakit

4) Pasal 1 Permenkes Nomor 1691/Menkes/Per/VIII/2011 tentang Keselamatan Pasien Rumah Sakit

Pasien berhak memperoleh keamanan dan keselamatan dirinya selama masa perawatan di rumah sakit dengan sebaik-baiknya yang dalam asas pelayanan kesehatan dikenal istilah "agroti salus lex suprema" atau keselamatan pasien adalah hukum yang tertinggi. Masalah keselamatan pasien merupakan hal yang sangat penting sebab menjadi acuan bagi setiap rumah sakit untuk melaksanakan kegiatannya. Keselamatan pasien juga berhubungan dengan efektifitas pelaksanaan teleradiologi sebagai bagian dari penunjang medik yang sangat bergantung pada adanya standar prosedur operasional, standar praktik dan standar kompetensi praktik teleradiologi di rumah sakit untuk meminimalisasi risiko (risk manajement) atau potensi risiko sehingga rumah sakit mampu memberikan jaminan pelayanan kesehatan kepada publik secara aman dan berkualitas. 
Namun ringkasnya teleradiologi sebagai suatu teknologi yang membantu dalam bidang radiologi harus menghormati hak pasien dan mengutamakan keselamatan pasien. Penting untuk menggarisbawahi bahwa teleradiologi tidak dimaksudkan untuk menggantikan metode pemberian asuhan tradisional atau peran dokter sebagai klinisi seperti konsultasi tatap muka dengan pasien.

\section{Aspek Hukum Pelaksanaan Teleradiologi dalam Pemenuhan Hak Pasien}

Sudikno Mertokusumo mengatakan bahwa kaedah hukum lazimnya diartikan sebagai peraturan hidup yang menentukan bagaimana manusia itu seyogyanya berprilaku serta bersikap di dalam masyarakat agar kepentingannya dan kepentingan orang lain terlindungi atau dalam arti sempit kaedah hukum adalah nilai yang terdapat dalam peraturan konkret. Diuraikan lebih lanjut, dilihat dari fungsi maka kaedah hukum pada hakekatnya adalah untuk melindungi kepentingan manusia atau kelompok manusia, sedangkan tujuan kaidah hukum tidak lain adalah ketertiban masyarakat. ${ }^{12}$

Pelaksanaan teleradiologi juga memerlukan pedoman yang jelas untuk dapat memberikan keadilan, kemanfaatan dan kepastian hukum dalam hubungannya terhadap pemenuhan hak pasien. Ini berarti teleradiologi haruslah memenuhi prinsip-prinsip dan aturan hukum yang berlaku maka aspek hukum yang mengatur teleradiologi diperlukan untuk mengkaji legalitas pelaksanaan, penggunaan dan peninjauan kelayakan terhadap aspek hukum teleradiologi.

Hal ini tentu saja berdampak pada pelayanan kesehatan berbasis teleradiologi yang menyebabkan penggunaan aplikasi dan platform menjadi terkomputerisasi dan secara langsung meletakkan tanggungjawab hukum pada tenaga kesehatan apabila terjadi tindak pidana $c$ ber ${ }^{13}$ pelanggaran hak maupun kelalaian medis. Meskipun konsep global mengenai teleradiologi sekarang sudah mapan tetapi konsep etiko dan legal seputar inovasi ini masih tidak jelas. Tentu kita tidak dapat menampik bahwa penggunaan teleradiologi sudah menjamur jauh mendahului eksistensi peraturan perundangundangan. Adagium hukum mengatakan, "het recht hinkt achter de feiten aan", yaitu hukum selalu berjalan di belakang peristiwa atau hukum selalu ketinggalan dari peristiwa (the right lies behind the facts). ${ }^{14}$

Keadaan semacam ini mengharuskan kita agar melihat pada tujuan hukum yang hendak dicapai, yaitu keadilan (gerechtigkeit), kemanfaatan (zweckmasigkeit) dan kepastian hukum (rechtssicherkeit). Penekanan pada tujuan hukum sebagai aspek hukum dalam pelaksanaan teleradiologi sangat penting agar perlindungan hak pasien dan tanggungjawab hukum dalam teleradiologi dapat memberikan keadilan dan kemanfaatan yang terjamin melalui sebuah kepastian hukum dalam bermasyarakat.

\section{a. Aspek Keadilan Pelaksanaan Teleradiologi}

Berbicara mengenai keadilan, kita umumnya memikirkan sebagai keadilan individual, yaitu keadilan yang tergantung dari kehendak baik atau buruk masing-masing individu. Artinya diharapkan bahwa setiap orang dapat bertindak dengan adil

\footnotetext{
${ }^{12}$ Sudikno Mertokusumo, 2006, Penemuan Hukum, Yogyakarta: Liberty, hlm. 11

${ }^{13}$ Antonius Maria Laot Kian, "Telemedicine dan Selfie-Medis: Anatomi Tanggungjawab Hukum Pidana Tenaga Kesehatan dalam Tindak Pidana Cyber", disajikan dalam Seminar Nasional "Cyber Law dalam Bidang Pelayanan Kesehatan dan Implikasinya Bagi Tenaga Kesehatan” Semarang 6 Mei 2017, hlm. 1.

${ }^{14}$ Ibid.
} 
terhadap sesamanya dalam situasi yang sama memperlakukan siapa saja tanpa diskriminatif. ${ }^{15}$

Pada konteks yang lebih luas, pelayanan teleradiologi memberikan keadilan yang merata sebagai bagian dari tanggungjawab negara untuk memberikan pelayanan kesehatan yang dapat dijangkau oleh seluruh masyarakat dengan biaya yang murah di seluruh pelosok negeri. Maksudnya adalah ketika kebutuhan akan akses pelayanan radiologi yang berkualitas dan cepat maka bukan hanya daerah perkotaan saja yang dapat menikmatinya, melainkan juga di daerah perbatasan, terpencil bahkan kepulauan terluar pun harus turut serta merasakannya. Melalui teleradiologi hambatan jarak dan waktu pun dapat ditanggulangi, semakin cepat dan tepat serta secara tidak langsung telah mengakomodiri hak atas kesehatan bagi masyarakat dalam pemenuhan hak-haknya untuk mendapatkan pelayanan kesehatan.

Sementara itu pada konteks yang lebih sempit, makna keadilan berarti harus sama rata dan seimbang antara hak dan kewajiban masing-masing pihak yang terlibat di dalamnya dan dilandasi oleh semangat keadilan yang nondiksriminatif. Seorang dokter spesialis radiologi dalam menjalankan tugasnya harus berlaku adil tanpa membeda-bedakan latar belakang seorang pasien untuk mendapatkan pelayanan darinya. Perlakuan yang adil ini sebagai cara untuk menghormati semua hak pasien dalam mendapatkan pelayanan teleradiologi di rumah sakit.

Tetapi masih saja ketidakadilan terjadi dalam pelaksanaan teleradiologi yang menimpa pihak pasien. Pada penjelasan sebelumnya telah dikemukakan bahwa beberapa hak pasien seperti hak atas informed consent, hak atas second opinion, dan hak atas keselamatan pasien di rumah sakit ternyata tidak terpenuhi dalam pelaksanaan teleradiologi. Tidak terpenuhinya hak pasien ini mengakibatkan terjadinya ketidakseimbangan antara hak dan kewajiban masing-masing pihak. Sehingga dengan demikian aspek keadilan dalam artian menjaga keseimbangan antara hak dan kewajiban antara masing-masing pihak di dalam pelaksanaan teleradiologi belum terwujud sebagaimana mestinya.

\section{b. Aspek Kemanfaatan Pelaksanaan Teleradiologi}

Jeremy Bentham mengatakan bahwa tujuan hukum adalah memberikan kemanfaatan dan kebahagiaan sebanyak-banyaknya kepada warga masyarakat dan hukum adalah sarana untuk mencapai tujuan tersebut. ${ }^{16}$ Kesenjangan dalam pelayanan kesehatan di bidang radiologi termasuk tidak meratanya persebaran dokter spesialis radiologi dan tersedianya fasilitas pelayanan kesehatan yang optimal secara tidak langsung menjadikan hak pasien tidak terpenuhi. Pelaksanaan teleradiologi mampu mengeliminasi semua kesenjangan tersebut sehingga dapat meningkatan ketepatan dan kecepatan diagnosis serta konsultasi medis di rumah sakit yang belum memiliki tenaga dokter spesialis tertentu.

Tetapi pada kenyataannya program teleradiologi mengalami banyak kendala sehingga mengakibatkan program ini berhenti di tengah jalan. Infrastruktur teknologi

\footnotetext{
15 Suwardi Sagama,: “ Analisis Konsep Keadilan, Kepastian Hukum dan Kemanfaatan dalam Pengelolaan Lingkungan, 2016, Mazahib Jurnal Pemikiran Hukum Islam, Volume XV, Nomor 1, Tahun 2016, ISSN 1829-9067, hlm. 25.

${ }^{16}$ Atip Latipulhayat,: “Khazanah: Jeremy Benhtham”, 2015, PADJADJARAN Jurnal Ilmu Hukum, Volume 2, Nomor 2, Tahun 2015, ISSN 2460-1543, hlm. 418.
} 
yang belum memadai, minimnya sumber daya manusia, regulasi yang belum jelas, minimnya sosialisasi kemudian menyebabkan tidak berjalannya teleradiologi, sehingga manfaat yang seharusnya diterima oleh pasien menjadi terhenti dan pasien tidak lagi mendapatkan haknya untuk merasakan manfaat ekspertise radiologi yang berkualitas.

Pada penjelasan sebelumnya telah diuraikan masalah apa saja yang menyebabkan vakumnya teleradiologi, maka prinsip kemanfaatan ditujukan untuk menguji dan mengevaluasi segala kebijakan dan peraturan yang ditetapkan oleh pemerintah. ${ }^{17}$ Sejalan dengan pemikiran tersebut, pelaksanaan teleradiologi perlu ditinjau kembali dengan mengatasi masalah terhentinya program tersebut. Permasalahan ini perlu diselesaikan agar teleradiologi dapat terus memberikan manfaat kepada seluruh masyarakat.

\section{c. Aspek Kepastian Hukum Pelaksanaan Teleradiologi}

Hukum tidak hanya terbatas pada masalah keadilan atau kemanfaatan semata tetapi juga harus memberikan suatu kepastian dan perlindungan hukum. L.J. van Apeldoorn sebagaimana dikutip oleh Peter Mahmud Marzuki mengatakan tujuan hukum adalah untuk mempertahankan ketertiban dalam masyarakat dan untuk mempertahankan ketertiban tersebut hukum harus secara seimbang melindungi kepentingankepentingan yang ada dalam masyarakat. ${ }^{18}$

Secara khusus pelaksanaan teleradiologi dalam konteks hukum belum diatur dalam regulasi tersendiri apabila dibandingkan dengan Malaysia yang sudah memiliki Telemedicine Act sejak tahun 1997 dan Singapura melalui Telemedicine National Guidelines sejak tahun 2015. Sejauh ini di Indonesia hanya merupakan bagian dari uji coba yang terdapat pada Kepmenkes No. HK.02.02/Menkes/409/2016 tentang Rumah Sakit Uji Coba Program Pelayanan Telemedicine Berbasis Video-Conference dan Teleradiologi serta yang terbaru melalui Kepmenkes Nomor HK.01.07/Menkes/650/2017 tentang Rumah Sakit dan Puskesmas Penyelenggara Uji Coba Program Pelayanan Telemedicine.

Tetapi bila diselidiki lebih jauh terdapat beberapa pasal dalam peraturan perundangundangan yang dapat digunakan sebagai payung hukum dari pelayanan kesehatan berbasis teleradiologi seperti:

1) Penjelasan Undang-Undang Nomor 29 Tahun 2004 tentang Praktik Kedokteran Pasal 28: Pelaksanaan praktik teleradiologi membutuhkan pelatihan berkelanjutan guna memastikan praktik teleradiologi yang aman dan bermutu.

2) Penjelasan Undang-Undang Nomor 36 Tahun 2009 tentang Kesehatan

a) Pasal 42: Teleradiologi memiliki manfaat untuk mendeteksi adanya penyakit dan mempercepat diagnosa sehingga dapat meningkatkan kualitas kesehatan masyarakat.

b) Pasal 44: Teleradiologi telah dilaksanakan melalui serangkaian uji coba melalui Keputusan Dirjen Bina Upaya Kesehatan dan Keputusan Meteri Kesehatan

${ }^{17}$ Ibid., 419

${ }^{18}$ Peter Mahmud Marzuki, 2006, Penelitian Hukum, Jakarta: Kencana, hlm. 58. 
tentang Pelaksanaan Telemedicine yang di dalamnya juga mengatur mengenai teknis dan alur pelayanan teleradiologi.

3) Penjelasan Undang-Undang Nomor 44 Tahun 2009 tentang Rumah Sakit

a. Pasal 5: Teleradiologi dilaksanakan untuk meningkatkan pelayanan radiologi diagnostik yang berkulitas, khususnya bagi fasilitas pelayanan terpencil yang tidak memiliki dokter spesialis radiologi.

b. Pasal 6 huruf j: Pelaksanaan teleradiologi membutuhkan perangkat teknologi dan alat kesehatan yang canggih sehingga pemerintah bertanggungjawab mendistribusikan perangkat teknologi dan alat-alat kesehatan untuk fasilitas pelayanan kesehatan yang membutuhkan.

4) Penjelasan Undang-Undang Nomor 19 Tahun 2016 tentang Perubahan Atas Undang-Undang Nomor 11 Tahun 2008 tentang Informasi Dan Transaksi Elektronik Pasal 26 ayat 1: Sistem teleradiologi mengandalkan jaringan internet untuk melakukan pertukaran data-data elektronik pasien, dan media elektronik sebagai wadah penyimpanan data-data tersebut sehingga setiap penggunaan data pasien di sistem teleradiologi untuk tujuan apapun kecuali untuk pembuktian di pengadilan.

5) Penjelasan Peraturan Pemerintah Nomor 82 Tahun 2012 tentang Penyelenggaraan Sistem dan Transaksi Elektronik

a) Pasal 10: Pelaksanaan teleradiologi sebagai sistem elektronik memiliki tenaga ahli di bidang IT untuk membantu rumah sakit untuk mengoperasikan aplikasi teleradiologi.

b) Pasal 11 huruf j: Teleradiologi merupakan sistem elektronik yang memiliki manfaat terhadap pengingkatan kualitas pelayanan publik dalam hal ini pelayanan kesehatan di fasilitas pelayanan kesehatan terpencil.

6) Penjelasan Peraturan Menteri Kesehatan Nomor 269/Menkes/Per/III/2008 tentang Rekam Medis Pasal 2: Penggunaan rekam medis elektronik pasien diperlukan sebagai bahan pertimbangan seorang dokter spesialis radiologi dalam melakukan ekspertise melalui teleradiologi untuk menegakkan diagnosis.

7) Penjelasan Peraturan Menteri Kesehatan Nomor 780/Menkes/Per/VIII/2008 tentang Penyelenggaraan Pelayanan Radiologi

a) Pasal 1 angka 2: Teleradiologi merupakan bagian dari radiologi diagnostik, sehingga penggunaannya dapat bermanfaat untuk meneggakkan diagnosa suatu penyakit.

b) Pasal 9: Pelaksanaan teleradiologi membutuhkan persetujuan seorang dokter spesialis radiologi untuk dapat melakukan tindakan radiologi diagnostik.

8) Penjelasan Peraturan Menteri Kesehatan Nomor 90 Tahun 2015 tentang Penyelenggaraan Pelayanan Kesehatan di Fasilitas Pelayanan Kesehatan Kawasan Terpencil dan Sangat Terpencil

a) Pasal 15: Teleradiologi merupakan bagian dari telemedicine yang bermanfaat untuk mempercepat dan menegakkan diagnosis di fasyankes yang terpencil dan sangat terpencil. 
b) Pasal 19 ayat 1: Pelaksanaan teleradiologi dapat meningkatkan kualitas kesehatan masyarakat di daerah terpencil dan sangat terpencil dengan memberikan pelayanan yang tepat dan cepat.

9) Penjelasan Kepmenkes Perubahan Standar Pelayanan Radiologi Diagnostik di Saranan Pelayanan Kesehatan pada bagian kebijakan sistem administrasi pelayanan radiologi diagnostik bahwa pembacaan hasil radiologi diagnostik dapat dilakukan melalui teleradiologi oleh dokter spesialis radiologi sesuai dengan standar PDSRI.

Semua payung hukum diatas memang belum mengungkapkan secara tegas tentang pelaksanaan teleradiologi dalam pelayanan kesehatan yang terkesan kabur dan tidak jelas. Ketidakjelasan ini menimbulkan ketidakpastian hukum terkait dengan pelaksanaan teleradiologi yang masih belum memiliki peraturan tersendiri. Meskipun sudah ada regulasi yang telah diberlakukan untuk memenuhi tuntutan pelaksanaan teleradiologi tetapi hanya bersifat teknis uji coba sehingga belum memadai untuk dapat mengimbangi kompleksitas teleradiologi agar tidak bersinggungan dan merugikan kepentingan pasien dalam ranah hukum.

\section{PENUTUP KESIMPULAN}

1. Pelaksanaan teleradiologi di rumah sakit sejauh ini masih sebatas uji coba dan mengalami banyak kendala yang disebabkan oleh keterbatasan jaringan infrastruktur, sumber daya manusia, minimnya sosialisasi pelaksanaan teleradiologi dan regulasi yang belum mengatur teleradiologi secara khusus sehingga belum bisa menyeluruh untuk dapat memenuhi hak pasien atas pelayanan teleradiologi. Adapun akibat dari keterbatasan tersebut menyebabkan tidak terpenuhinya hak-hak pasien, khususnya hak atas informed consent, hak atas second opinion dan hak atas keselamatan pasien di rumah sakit. Pertama hak atas informed consent yang tidak didapatkan oleh pasien maupun keluarganya untuk memperoleh informasi sebelum menyetujui tindakan yang boleh dilakukan atau tidak boleh dilakukan kepada dirinya. Kedua, hak atas second opinion yang mana merupakan hak pasien untuk meminta pedapat kedua mengenai diagnosis penyakitnya juga tidak terpenuhi padahal second opinion dalam teleradiologi menjadi sangat penting dikarenakan ekspertise suatu gambar atau foto radiologi memerlukan keahlian dan kepakaran untuk menentukan keakuratan suatu penyakit. Ketiga, hak atas keselamatan pasien di rumah sakit juga tidak terpenuhi sebagai bagian dari rentetan tidak terpenuhinya kedua hak diatas khususnya dalam hal kelengkapan data klinis (rekam medis) pasien yang tidak disertakan dalam proses ekspertise teleradiologi yang berpotensi mempengaruhi hasil interpretasi, pengambilan tindakan dan penatalaksanaan selanjutnya.

2. Aspek hukum pelaksanaan teleradiologi di rumah sakit berupa hal-hal yang berkaitan dengan tujuan hukum yakni keadilan, kemanfaatan dan kepastian hukum. Aspek keadilan dimaksudkan adalah pelayanan teleradiologi tidak bersifat diskriminatif dan berfungsi menjaga keseimbangan hak serta kewajiban antara dokter dan pasien akan tetapi pada pelaksanaanya pasien tidak mendapatkan sebagian haknya. Selanjutnya aspek kemanfaatannya adalah teleradiologi ternyata memberikan manfaat besar bagi pasien yang berada di daerah pedesaaan, terpencil dan kepulauan untuk dapat 
merasakan pelayanan teleradiologi yang berkualitas serta meningkatkan mobilitas bagi dokter di rumah sakit tetapi dengan vakumnya teleradiologi mengakibatkan manfaat teleradiologi tidak lagi dapat dirasakan. Sementara itu aspek kepastian hukumnya adalah secara umum teleradiologi telah dilaksanakan dengan mengacu pada peraturan perundang-undangan yang berlaku secara umum, seperti seperti UU Kesehatan, UU Rumah Sakit, UU ITE, PP Penyelenggaraan Sistem dan Transaksi Elektronik, Permenkes Penyelenggaraan Radiologi, Kepemenkes Perubahan Standar Pelayanan Radiologi Diagnostik di Sarana Pelayanan Kesehatan, Kepmenkes Rumah Sakit Uji Coba Program Pelayanan Telemedicine Berbasis Video-Conference dan Teleradiologi serta Kepmenkes Rumah Sakit dan Puskesmas Penyelenggara Uji Coba Program Pelayanan Telemedicine tetapi hanya berlaku secara umum dan tidak mengatur secara spesifik sehingga tidak dapat mengimbangi kompleksitas teleradiologi untuk memberikan jaminan kepastian dan perlindungan hukum bagi pasien untuk mendapatkan hak-haknya terhadap pelayanan kesehatan berkualitas.

\section{SARAN}

1. Bagi Pemerintah bersama dengan pihak-pihak yang terkait agar dapat segera mungkin menyusun regulasi mengenai telemedicine dalam hal ini teleradiologi yang mengatur standar pelayanan teleradiologi, keamanan dan kerahasiaan data elektronik pasien dan pengaturan penyelesaian sengketa sehingga dapat memberikan keadilan, kemanfaatan dan kepastian hukum bagi pemberi dan penerima pelayanan teleradiologi.

2. Bagi Rumah Sakit agar dapat membuat kebijakan internal berupa standar prosedur operasional yang mengatur mengenai pelayanan teleradiologi sehingga dapat memberikan pelayanan yang maksimal dengan tetap memperhatikan hak-hak pasien. Rumah sakit juga perlu mengadakan pelatihan dan pendidikan berkelanjutan serta seminar mengenai teleradiologi untuk meningkatkan kualitas SDM yang tentu saja bekerjasama dengan organisasi profesi yang terkait serta melaksanakan evaluasi berkala terhadap tindakan dan kebijakan yang telah diterapkan terkait dengan teleradiologi.

3. Bagi Pasien perlu untuk menyadari hak-haknya dalam pelayanan teleradiologi dengan cara mencari tahu mengenai hak pasien atau menanyakan langsung ke tenaga kesehatan di rumah sakit untuk menghindari degradasi haknya sebagai pasien. Hal ini menjadi penting bagi pasien sebab dengan kemajuan teknologi di bidang kesehatan dapat mempengaruhi kualitas pelayanan kesehatan dan kepuasaan pasien. 


\section{DAFTAR PUSTAKA}

American College of Radiology, "ACR Standard for Teleradiology", diakses pada 28 September 2017, https://www.acr.org/Practice-Management-QualityInformatics/Legal-Practices/Teleradiology

Antonius Maria Laot Kian, "Telemedicine dan Selfie-Medis: Anatomi Tanggungjawab Hukum Pidana Tenaga Kesehatan dalam Tindak Pidana Cyber", disajikan dalam Seminar Nasional "Cyber Law dalam Bidang Pelayanan Kesehatan dan Implikasinya Bagi Tenaga Kesehatan" Semarang 6 Mei 2017.

Atip Latipulhayat,: "Khazanah: Jeremy Benhtham", 2015, PADJADJARAN Jurnal Ilmu Hukum, Volume 2, Nomor 2, Tahun 2015, ISSN 2460-1543.

Dian Noeswantri,: "Pemenuhan Hak Anak Dalam Perspektif HAM", 2004, Dinamika HAM, Volume 4, Nomor 1, Januari 2004, ISSN 1410-3982.

DTPK (Daerah Tertinggal, Perbatasan dan Kepulauan), diakses pada 20 April 2017, https://rebanas.com/kamus/kesehatan/dtpk-daerah-tertinggal-perbatasan-dankepulauan

Peter Mahmud Marzuki, 2006, Penelitian Hukum, Jakarta: Kencana.

Profil Kesehatan Indonesia 2015, Kementerian Kesehatan Republik Indonesia, diakses pada 23 September 2017, www.depkes.go.id/.../profil-kesehatan-indonesia/profilkesehatan-Indonesia-2015.pdf

Pusat Komunikasi Publik Sekretariat Jenderal Kementerian Kesehatan RI, “Menkes Harapkan Kemkominfo Dukung Pemanfaatan Teknologi Informasi Dan Komunikasi (TIK) Di Bidang Kesehatan", 31 Desember 2014, diakses pada 14 Maret 2017, http://www.depkes.go.id/article/print/15010200022/menkes-harapkan-kemkominfodukung-pemanfaatan-teknologi-informasi-dan-komunikasi-tik-di-bidang-keseh.html

Richard Wotton, et.al., 2009, Telehealth in the Developing World, London: Royal Society of Medicine Press Ltd.

Scott Berger and Barry Cepelewicz, 1995, "Medical-Legal Issues in Teleradiology", American Roentgen Ray Society, diakses dari http://sci-hub.tw/10.2214/ajr.166.3.8623616.

Sudikno Mertokusumo, 2006, Penemuan Hukum, Yogyakarta: Liberty.

Suwardi Sagama,: “ Analisis Konsep Keadilan, Kepastian Hukum dan Kemanfaatan dalam Pengelolaan Lingkungan, 2016, Mazahib Jurnal Pemikiran Hukum Islam, Volume XV, Nomor 1, Tahun 2016, ISSN 1829-9067.

Wisnubro, "Sebanyak 1.250 Dokter Spesialis akan Disebar ke Pelosok Tanah Air" 24 Februari 2017, diakses pada 29 Agustus 2017, https://jpp.go.id/humaniora/kesehatan/302825inilah-program-kemenkes-agar-tenaga-kesehatan-merata-di-tanah-air

World Health Organization,: "Telemedicine: Opportunities and Developments in Member States: (Report On The Second Global Survey On eHealth)", 2010, WHO Press: Global Observatory for eHealth Series, Volume 2, 2009 ISSN 2220-5462. 


\section{Perundang-undangan}

RI, Undang-Undang Dasar Negara Republik Indonesia Tahun 1945

RI, Undang-Undang Nomor 39 Tahun 1999 tentang Hak Asasi Manusia

RI, Undang-Undang Nomor 29 Tahun 2004 tentang Praktik Kedokteran

RI, Undang-Undang Nomor 36 Tahun 2009 tentang Kesehatan

RI, Undang-Undang Nomor 44 Tahun 2009 tentang Rumah Sakit

RI, Undang-Undang Nomor 19 Tahun 2016 tentang Perubahan Atas Undang-Undang Nomor 11 Tahun 2008 tentang Informasi Dan Transaksi Elektronik

RI, Peraturan Pemerintah Nomor 82 Tahun 2012 tentang Penyelenggaraan Sistem dan Transaksi Elektronik

RI, Peraturan Menteri Kesehatan Nomor 269/Menkes/Per/III/2008 tentang Rekam Medis

RI, Peraturan Menteri Kesehatan Nomor 290/Menkes/Per/III/2008 tentang Persetujuan Tindakan Kedokteran

RI, Peraturan Menteri Kesehatan Nomor 780/Menkes/Per/VIII/2008 tentang Penyelenggaraan Pelayanan Radiologi

RI, Peraturan Menteri Kesehatan Nomor 1691/Menkes/Per/VIII/2011 tentang Keselamatan Pasien Rumah Sakit

RI, Peraturan Menteri Kesehatan Nomor 90 Tahun 2015 tentang Penyelenggaraan Pelayanan Kesehatan di Fasilitas Pelayanan Kesehatan Kawasan Terpencil dan Sangat Terpencil

RI, Keputusan Menteri Kesehatan Nomor 410/Menkes/SK/III/2010 tentang Perubahan Atas Keputusan Menteri Kesehatan Nomor 1014/Menkes/SK/XI/2008 tentang Standar Pelayanan Radiologi Diagnostik di Sarana Pelayanan Kesehatan

RI, Keputusan Direktur Jenderal Bina Upaya Kesehatan Kementerian Kesehatan Nomor HK.02.03/V/0209/2013 tentang Pelaksanaan Pilot Project Telemedicine dan Penunjukan Fasilitas Pelayanan Kesehatan Telemedicine Bidang Teleradiologi dan Telekardiologi

RI, Keputusan Menteri Kesehatan Nomor HK.02.02/Menkes/409/2016 tentang Rumah Sakit Uji Coba Program Pelayanan Telemedicine Berbasis Video-Conference dan Teleradiologi

RI, Keputusan Menteri Kesehatan Nomor HK.01.07/Menkes/650/2017 tentang Rumah Sakit dan Puskesmas Penyelenggara Uji Coba Program Pelayanan Telemedicine 